\title{
Research on the Talent Training of Colleges and Universities under the Background of Industry 4.0
}

\author{
Wenli Huang ${ }^{1, a}$ \\ ${ }^{1}$ School of Art and Design, Hubei Engineering University \\ a370602262@qq.com
}

Keywords: Industry 4.0; Talent training of universities; Strategies

\begin{abstract}
With the gradual acceleration of the process of global Industry 4.0, in order to meet the objective requirements of China's industrial modernization construction, the major comprehensive universities in China have also strengthened the construction of talent training strategies. Based on the talent training of universities under the background of Industry 4.0, this paper introduces the meaning and characteristics of Industry 4.0, introduces the current situation of the talents training model of the universities in China, analyzes the new requirements of Industry 4.0 on engineering talents training of universities, judges the implementation strategies of talent training of universities in the background of Industry 4.0 and hopes to provide new ideas for the smooth development of talent training in the universities in China.

From the perspective of the development stages of human civilization, human society has experienced four stages of development since it entered the industrial revolution in the $18^{\text {th }}$ century. In this process, the changes of production modes, production status and the relationship between machinery and human are obvious. At present, China is in a critical period of socialist modernization, and the state's emphasis on Industry 4.0 is self-evident. In order to better analyze the talent training model and exhibition in the context of Industry 4.0, it is necessary to introduce the meaning and characteristics of Industry 4.0.
\end{abstract}

\section{The Meaning and Characteristics of Industry 4.0}

The meaning of Industry 4.0

It is known to all that human society has experienced four stages of development since it entered the industrial revolution in the $18^{\text {th }}$ century. At present, we are in the fourth industrial revolution. From the point of time, Industry 4.0 was first proposed in Germany in April 2013, which indicates that human industrial technology has entered the era of networking, intelligence and information, which does not only greatly liberate industrial productivity, but also allows human enter an era of intelligence and information.

The characteristics of Industry 4.0

The characteristics of Industry 4.0 determine its position in the liberation of human civilization's productive forces. According to relevant literature research, Industry 4.0 mainly includes the following five specific characteristics.

First, interconnection. In fact, interconnection is a perfect combination of equipment, production lines, suppliers and customers. In the entire production and sales process, almost no human is needed to operate to complete the above content ${ }^{[1]}$.The effective connection of the information physics system avoids errors in the interconnection process and requires no human intervention.

Second, integration. Good integration is another important characteristic of Industry 4.0. From an objective point of view, the biggest difference between Industry 4.0 and 3.0 is good integration. Combining data, information, perception and Internet terminals to complete the integration of automatic generation, automatic packaging, and automatic sales, which does not only save costs or increase efficiency, but also completely frees people from heavy labor.

Third, data. Data feature is one of the unique characteristics of Industry 4.0, which mainly includes the interaction content between information and production equipment and Internet terminals under the conditions of Big Data era, and relates to the specific content of data processing 
and information feedback.

Fourth, innovation. Innovation is the cornerstone of manufacturing development, and it is also the key to the continuous development and progress of Industry 4.0.

Fifth, transformation. With the advent of Industry 4.0 era, the current demand for various types of service-oriented talents continues to increase, and workers' demands for simple and repetitive labor continue to decrease. This is also the inspiration to the future adjustment of the talent market in China of Industry 4.0 era.

\section{The Status Quo of University Talents Training Model in China}

At present, the training specifications for talented people in universities of our country are relatively uniform. The talents cultivated through the methods of classroom learning, passing exams and graduation reply have a certain degree of homogeneity. ${ }^{[2]}$ The mode of production of talents is so fixed that the individual differences in talents are not strong, which even cannot meet the objective requirements of Industry 4.0 for talents at this stage. Although China's universities have strengthened the reform of teaching methods in recent years, there are still problems, such as the talent model is single, the teaching content focuses too much on theory rather than practice, the curriculum system is too concentrated without pertinence or recognition, and students' awareness and enthusiasm of independent learning is not strong, which does not only affect the construction of China's industrial modernization, but also does not help students reflect their own values or obtain more rewarding returns.

\section{Industry 4.0 Puts Forward New Requirements for Engineering Talents Training of Universities}

Once Industry 4.0 is proposed, it is regarded as the main trend of future industrial development by various countries. Combined with the development status of China's Industry 4.0, its requirements for college engineering and technical talents are mainly concentrated in the following aspects:

Good engineering awareness

Engineering awareness is a general system awareness, not only including economic and social awareness, times awareness, innovative practices awareness, but also managing awareness, moral awareness and many other aspects. ${ }^{[3]}$ With the development of the times, the value and role of engineering awareness has gradually been recognized by people and developed and changed with the times.Engineering awareness cannot only quickly solve complex and ever-changing engineering problems at work, but also can help the staff to enhance the innovative ability. With a keen observation ability, it can sort out higher economic and engineering technology solutions to optimize industrial allocation and production patterns and improve production efficiency and economic benefits.

The basic ability of cross-professional learning

In the beginning, China's higher engineering education was carried out by studying the education model of the former Soviet Union and was more adapted to the planned economy period. With the development of the times, China has now begun to implement a socialist market economy with Chinese characteristics and has achieved good construction results, but the talent training mode has not changed. Judging from the talent production model, the training of university engineering talents in China places an excessive emphasis on specialization and the characteristics of professional counterparts, and pays less attention to the needs of compound talents in the new era. With the continuous development of Industry 4.0 era, current information processing, teamwork and good communication skills have become the qualities which are necessary for outstanding talents. As a result, universities must also accelerate the reform of teaching models and provide more abundant learning channels to help students acquire the ability in cross-professional learning, in order to obtain more complex knowledge and create conditions for their work in the new era.

Understand technology and manage

Industry 4.0 is a technological revolution and it is also a management revolution. From an 
objective point of view, the management of small and medium-sized enterprises is relatively loose, and the management capabilities of personnel are not demanding. With the advent of Industry 4.0 era, the intensification of enterprises will become more and more serious, and more management elements will be concentrated in large enterprises. In order to achieve centralized management, everyone must understand management, otherwise they will be eliminated by the market.To understand management, it is also necessary to understand technology, so that it can find loopholes in work and optimize it in a timely manner with professional technical insights, so as to do a good job in production planning and operation analysis. This is also the new requirement which is put forward by Industry 4.0 era for talents.

\section{University Talents Training Strategies in the Background of Industry 4.0}

The arrival of Industry 4.0 has pointed out the direction for talent training in universities in China. As a university with strong engineering expertise, it should focus on the specific work in the following areas.

1 Strengthen engineering practice

In our country, most colleges and universities have the problem of overemphasizing theory and ignoring practice. Although in recent years, many colleges and universities have proposed a combination of practical and theoretical teaching model and achieved certain results,they still cannot meet the objective requirements of Industry 4.0. As the core of the development of the manufacturing industry in the era of Industry 4.0, in order to maintain strong creativity, it is necessary to strengthen the engineering practice training for talents. In the process of practical teaching, teachers should also do a good job in guiding engineering innovation so that students can understand the value and characteristics of the combination of theory and practice, and do a good job of the dynamic generation process of operational learning. ${ }^{[4]}$ Students can gradually grasp the practical ability, enhance the logical level of creative thinking, and create conditions for realizing the requirements of Industry 4.0 and enhancing their own value.

Develop students' engineering awareness

Engineering awareness is a relatively new vocabulary, but it always runs through the development of China's manufacturing industry. As the main place for students to learn knowledge, the classroom is also a place for teachers to convey ideas and awareness to students. Students' basic knowledge and professional knowledge often come from classroom learning, but most of their academic ideas and thinking patterns are formed in daily practice. Teachers must do a good job in classroom guidance to help students recognize the importance of engineering awareness, and then gradually cultivate interests in engineering learning and hobbies and enhance their enthusiasm to participate in engineering practice. Training students' engineering awareness must rely on practical courses. For example, in engineering environment, teachers help students create learning situations where students learn the use of equipment and the manufacturing methods of various devices. Students also need to experience hands-on skills and to enhance on-site resilience in the work so that they can better handle all kinds of emergencies and their own engineering awareness is also inadvertently trained.

Set up interdisciplinary professional courses

Industry 4.0 puts forward higher requirements for talent training, including the requirements for "complex" talents. Colleges and universities should strengthen compound talents training, provide students with more choice channels, keep students' good values, and help them establish independent thoughts and personality, at the same time, help them acquire more knowledge reserves and to improve work ability and skills after entering the working positions. Colleges and universities can focus on the above-mentioned interdisciplinary professional courses according to their own situation. Of course, other courses can also be provided for students to choose, so as to enhance their learning awareness. At the same time, they can also improve students' management skills and create conditions for them to become higher-level management talents.

Do a good job in the joint training of school and enterprise

The joint training of school and enterprise is an important way to improve the professional 
quality of talents, and it is also one of the types of work that is consistent with the basic orientation of the "production, education and research" policy that China has put forward. ${ }^{[5]}$ Enterprises have strong capital and good practice links. Colleges and universities have a talent pool and a good academic research atmosphere. Through targeted personnel training, enterprises can save on personnel costs and improve the quality of talent recruitment. School-enterprise cooperation in running schools can improve the quality of laboratories levels and help students strengthen their practical ability. Finally, the creation of dual-professional teachers can enhance the level of teachers' practice and create conditions for the successful completion of practical teaching tasks.

\section{Conclusion}

With the advent of Industry 4.0 era, the state has put forward more stringent high standards and high requirements for college talents. In order to achieve this goal, the author also puts forward specific ideas and suggestions for training students' engineering awareness, strengthening engineering practice, setting up interdisciplinary professional courses and strengthening school-enterprise cooperation with the hope to lay a solid foundation for training outstanding engineering and technical talents in China and to contribute to the development of our country to a strong modern socialist country.

\section{References}

[1] Xu Jingwei, Yang Chengsan,Fu Yingying. Analysis on the Promotion of Talent Cultivation in Colleges and Universities under the Background of Intelligent Manufacturing and Industry 4.0[J]. Reform and Opening, 2017(16):111-113.

[2] Wang Xiaoli, Xin Yong. Practice Reform of University Engineering Undergraduate Talent Cultivation in Industry 4.0 Era[J]. China Educational Technology Equipment, 2017(10):139-141.

[3] Zhang Ye, Li He, Zhuang Wen. Innovative Research on Talent Cultivation Mode in Colleges and Universities in the Background of Industry 4.0[J]. Bulletin of Economics and Trade, 2017(09): 285.

[4] Yan Ruosi,Wei Sainan,Wu Lei.Current Situation and Strategy of Talent Cultivation in Universities and Strategic Emerging Industries_-Based on Industry 4.0 Perspective[J]. Journal of Shijiazhuang Vocational and Technical College, 2017, 29(01): 60-64.

[5] Yu D, Peng L. When does Inferring Reputation Probability Countervail Temptation in Cooperative Behaviors for the Prisoners' Dilemma Game? [J]. Chaos, Solitons \& Fractals, 2015, 78: 238-244. 